\title{
Clauss Method
}

National Cancer Institute

\section{Source}

National Cancer Institute. Clauss Method. NCI Thesaurus. Code C142334.

An in vitro method to determine the rate of fibrin clot formation, in which diluted plasma

(with thrombin-dependency removed) is mixed with high concentrations of thrombin.

This reaction is run in tandem with a control sample and compared. 